\title{
HABITABILIDAD Y DISEÑO: LA INTERDEPENDENCIA RADICAL Y LA TERRAFORMATIVIDAD DE LAS CIUDADES
}

\author{
Arturo Escobar* \\ Profesor de Antropologia Emérito, University of North Carolina, Chapel Hill \\ https://dx.doi.org/10.12795/astragalo.2018.i25.03
}

\section{RESUMEN}

Este artículo se basa en la premisa de que la crisis civilizatoria actual implica una crisis de los modos occidentales de habitar que han erosionado el modo de vida sistémico basado en la interdependencia radical entre humanos y no humanos. La tierra, en pocas palabras, ha sido exiliada de la ciudad. Es posible imaginar y diseñar nuevos modos de habitar incorporando formas de vida relacionales en los paisajes urbanos, dentro de una concepción comunal amplia y abierta. Con este fin, el artículo presenta los conceptos de rurbanización y la re-equipamiento ontológico de las ciudades como estrategias de diseño ontológico para volver a terraformar la ciudad. Se resume tanto el 'giro relacional' en los estudios urbanos, -enfoques actuales para repensar la ciudad en términos de redes com- plejas y ensamblajes compuestos por actores y procesos humanos y no humanos-, y los recientes intentos de reintegración de la naturaleza en la ciudad, como la planeación y el diseño urbano biofílico. Aunque no están dirigidas explícitamente a volver a terraformar la ciudad, estas tendencias proporcionan importantes elementos teóricos, políticos y pragmáticos para desarrollar proyectos para tal proceso de terraformar.

El documento continúa presentando una propuesta arquitectónica particular de rurbanización en Colombia, concebida como una posible nueva fusión entre el campo y la ciudad a través de diseños habitacionales destinados a permitir una producción significativa de alimentos como una característica central del entorno construido. La sección final des-

\footnotetext{
* Profesor de Antropologia Emerito, University of North Carolina, Chapel Hill. Profesor Ad-hoc, Doctorado en Diseño y Creación, U. de Caldas, Manizales, Colombia. Profesor Ad-hoc, Doctorado en Ciencias Ambientales, U. del Valle, Cali.
} 
cribe las nociones de autonomía, comunidad y pluriversalidad derivadas de las luchas territoriales latinoamericanas como fuentes de inspiración para el habitar urbano relacional. La conclusión, finalmente, demuestra la dimensión civilizatoria de re-imaginar las formas actuales de habitabilidad.

- Palabras-Clave: habitabilidad; crisis civilizatoria; metroajuste; rurbanización; diseño ontológico; ciudades biofílicas.

\section{INTRODUCCIÓN: EL EXILIO DE LA TIERRA DE LA CIUDAD ${ }^{1}$}

La tierra ha sido desterrada de la ciudad. Por "Tierra" quiero decir, basado tanto en cosmovisiones indígenas como en conceptos de la teoría biológica y social contemporánea, la interdependencia radical de todo lo que existe, el hecho indudable de que todo existe porque todo lo demás existe, que nada preexiste a las relaciones que lo constituyen. La noción de "Tierra" señala la capacidad de la vida para la autoorganización, el flujo de la vida que se despliega incesantemente en formas, fuerzas, comportamientos y relaciones cambiantes, y el hecho de que las entidades, procesos y formas

1 Las ideas de este documento se presentaron por primera vez como la Conferencia Anual de Geoforum en la Reunión Anual de la Asociación Americana de Geógrafos (AAG), Nueva Orleans, del 10 al 14 de abril de 2018. Mi especial agradecimiento a la revista, especialmente a sus editores Sarah Hall y Robert Fletcher (actual) y Padraig Carmody (anterior) por su invitación y sugerencias útiles, y a Kiran Asher, Julie Cupples y David Simon por sus comentarios constructivos en la sesión. Gracias también a Harold Martínez, Tony Fry, Verónica Gago y Laura Forlano por compartir generosamente sus trabajos conmigo. Este documento debe verse como el esquema de un programa de investigación más que el resultado de una investigación ya realizada. Como tal, el lector no debe esperar una revisión completa de las literaturas pertinentes. están siempre en un proceso de co-surgimiento dependiente. Tomo esta noción de la Tierra como el horizonte para una praxis de vida renovada, y como la base para el acto esencial del habitar humano. ${ }^{2}$

El exilio de la Tierra de la ciudad es un reflejo de una doble anomalía civilizatoria: por un lado, la construcción de ciudades sobre la base de su separación del mundo viviente no humano, desde la polis clásica griega -si no antes-, y de manera constante con el avance del patrón reticular como forma urbana primaria; por otro lado, la tendencia hacia el menosprecio histórico de todo lo que no es la ciudad: todas las formas de vida rural; culturas indígenas y étnicas; nómadas, migrantes e incluso ocupantes ilegales que se niegan a cumplir con las reglas modernas de habitabilidad. Sin duda, la relación entre el campo y la ciudad implica una poderosa constelación semántica, que incluye el campo, la ciudad, los espacios intocados, lo pastoral y, por supuesto, la naturaleza. A pesar de esta complejidad, ha persistido una cierta asimetría, afamadamente encapsulada por Raymond Williams. (1973: 2):

El campo reúne sobre sí la idea de un estilo de vida natural: de paz, inocenciay virtud simple. Mientras que la ciudad fue concebida como un centro de progreso: de erudición, de comunicación, de

2 Estoy utilizando una noción de vida cercana a la defendida por las teorías de complejidad, autoorganización y emergencia. Un tratado exhaustivo sobre los diversos aspectos que conforman estas teorías es Capra y Luisi (2014). La característica esencial de todos los sistemas vivos es que son autocreados, es decir, autopoieticos, un concepto desarrollado por los científicos cognitivos chilenos Maturana y Varela. Para una descripción lúcida y sucinta de la independencia radical en biología, véase Sharma (2015). 
luces. También prosperaron las asociaciones hostiles: se vinculó a la ciudad con un lugar de ruido, de vida mundana y de ambición; y al campo, con el atraso, la ignorancia yla limitación. El contraste entre el campo yla ciudad, como dos estilos fundamentalmente distintos de vida, se remonta a la época clásica.

La ciudad llegó a ser vista como "una forma distintiva de civilización" (p. 1), vinculada al desarrollo del capitalismo y el colonialismo, comenzando en Inglaterra y llegando a la mayor parte del mundo, culminando en las capitales metropolitanas (Williams 1973: 279). -288). En todo momento, la interacción siempre cambiante entre el campo y la ciudad tenía un telos asumido, impulsado por la industrialización: "Todo el campo se convertirá en 'ciudad'; esa es la lógica de su desarrollo” (p. 284). Así surgió una conciencia colectiva, con la ciudad moldeando imágenes del futuro, ya sea maravillosas o tristes, magníficas o apocalípticas, ya sea conduciendo a la crisis o al progreso perpetuo; muchas de estas imágenes fueron alimentadas por primera vez por el Londres del siglo XIX (Williams 1973: 272278). También hubo una cierta idealización del campo que alcanzó expresiones dramáticas en el pastoralismo estadounidense, ya sea en la idea de que Estados Unidos es el sitio de un nuevo comienzo, todo un hemisferio intacto, o como una vasta extensión de naturaleza intocada, donde uno podría encontrar refugio de la abrumadora complejidad de la civilización urbana. Como lo han observado Leo Marx (1964) y William Cronon (1995), estos sentimientos, como la "naturaleza intacta" y los paisajes que suponen, son modos de conciencia histórica e invenciones culturales producidos por dicha civilización.

A pesar de estas complejidades, creo que es justo afirmar la existencia de una asimetría persistente; es como si todo lo bueno-civilidad, democracia, cultura, ciencia, arte- viniera de la ciudad; poco vino del campo, particularmente de la vida campesina. ¿Podría esta anomalía civilizatoria ser parcialmente revertida? ¿Podríamos encontrar pistas importantes para repensar las ciudades en aquellos espacios vilipendiados que se encuentran más allá de los confines de las ciudades, enfrentados como estamos con la crisis multifacética de clima, energía, alimentos, desigualdad, pobreza y significado causadas por la erosión progresiva de la relacionabilidad? ¿Podría la vida relacional mantenida históricamente por los campesinos y los pueblos indígenas, a pesar de las contradicciones, proporcionar ideas y estrategias para reconstruir ciudades? ¿Podrían las luchas ontológico-políticas de muchos grupos rurales y forestales en defensa de sus territorios y mundos contra las operaciones extractivas, basadas deliberadamente en la vida comunal y relacional, ocultar lecciones reveladoras para repensar y repolitizar el habitar urbano?

Esta es la visión principal que inspira este artículo. Una hipótesis más tangible basada en todo ello podría ser la siguiente: la crisis actual es una crisis de los modos de habitar heteropatriarcales, coloniales y capitalistas occidentales que han erosionado el modo de vida sistémico basado en la interdependencia radical. Es posible imaginar y diseñar nuevos modos de habitar incorporando modos de vida relacionales en los paisajes urbanos, dentro de una concepción comunal amplia y abierta. Existen 
pistas importantes para el replanteamiento y la reconstrucción relacional de las ciudades en las luchas territoriales autónomas de algunos grupos contra las actividades extractivas (en gran parte, pero no solo, en el Sur Global). Para ello, sin embargo, se requiere el rediseño ontológico del diseño, lejos de sus orientaciones funcionalistas e instrumentales y hacia los principios y objetivos relacionales.

Esta hipótesis implica tres operaciones epistémicas: la constitución de la habitabilidad como un dominio para el pensamiento y la praxis espacio-territorial; la refundación del diseño como una práctica cultural, técnica y política para otras formas de habitar; y el reconocimiento de las formas relacionales de ser y de habitar como condiciones para las transiciones al pluriverso. Para fundamentar esta hipótesis múltiple, esbozaré dos conceptos: la "rurbanización" y el "reequipamiento ontológico". Ellos proporcionarán la base para establecer los rudimentos de un marco para terraformar ${ }^{3}$ la ciudad.

La parte I de este artículo presenta la idea de la crisis de habitabilidad. Argumenta que las formas de habitabilidad y urbanismo desapegadas de la Tierra descentralizadas (no terraformadas) son fundamentales para la crisis civilizatoria del sistema heteropatriarcal

3 Nota del Traductor y del Autor: "El termino en inglés es re-earthing, que se refiere a una nueva integración de la naturaleza y la ciudad desde una perspectiva radicalmente relacional. Re-earthing es muy difícil de traducir al español. Aquí hemos optado por traducirlo como "terraformar" (sugerencia del traductor), aunque recibimos sugerencias de alternativas tales como "re-enraizar", "re-arraigar", "re-enterrar", "re-terriar", "re-plantar", "terracear" y "terruñar". El autor agradece a Alfredo Gutiérrez, Lina Álvarez, Marisol de la Cadena, Ángela María Franco y Andrea Botero por estas sugerencias. Las lectoras y lectores podrán imaginar otros términos a partir del contexto del artículo". capitalista moderno/colonial del mundo en la actualidad. La parte II resume los enfoques relacionales emergentes de la ciudad. Aunque no tienen el objetivo explícito de terraformar la ciudad, al repensar la ciudad en términos de redes complejas y ensamblajes entre entidades, procesos e infraestructuras, proporcionan importantes elementos teóricos, políticos y pragmáticos para avanzar en los proyectos de terraformatividad. La Parte III presenta una propuesta particular para la terraformatividad, concebida como una posible nueva fusión entre el campo y la ciudad a través de diseños arquitectónicos que podrían permitir que las viviendas urbanas sean infundidas con formas campesinas, particularmente a través de la instalación de la producción de alimentos como elemento central del entorno construido.

Esta última propuesta, desarrollada por el arquitecto y diseñador colombiano Harold Martínez Espinal, es un ejemplo perspicaz del terraformar. La Parte IV presenta el marco de Tony Fry sobre los reequipamientos ontológicos urbanos, esbozado por este autor desde el punto de vista del diseño ontológico. El reequipamiento ontológico se presenta como una perspectiva amplia para el desarrollo de proyectos de terraformatividad. La Parte $\mathrm{V}$ presenta brevemente el replanteamiento de la geógrafa Ananya Roy de la interfaz ruralurbana y el marco de las ciudades biofílicas de Timothy Beatley para reforzar la hipótesis de la rurbanización. Esta parte termina con una breve discusión de las nociones de autonomía, comunalidad y pluriversalidad como fuentes de información para el habitar relacional urbano. La conclusión, finalmente, da cuenta de la dimensión civilizatoria de re-imaginar las formas actuales de habitabilidad. 


\section{EL ESTADO DE LAS CIUDADES, CRISIS DE HABITABILIDAD Y TRANSICIONES CIVILIZATORIAS}

Los debates promovidos por Hábitat III, la reunión de las Naciones Unidas convocada por UN-Hábitat en octubre de 2016, el evento más influyente en el campo del urbanismo que se realiza cada 20 años, brindan un punto de partida iluminador para comprender el estado de los estudios urbanos. Como quedó expresado en un volumen crítico sobre la cumbre desde una perspectiva de América Latina, gran parte de lo que se ha hecho en términos de diseño y planificación urbana, al menos desde la tristemente famosa Carta de Atenas de 1933, ha servido para poner la planificación al servicio de los intereses privados, a pesar de las intenciones declaradas de proporcionar infraestructura adecuada para ciudades en crecimiento y de promover viviendas para los pobres (Borja y Carrión 2017). Esta situación se intensificó con los discursos neoliberales urbanos de "ciudades competitivas", ciudades de innovación y ciudades inteligentes.

El resultado ha sido la creciente especulación de la propiedaden forma de megaproyectos, viviendas de alto nivel y la proliferación de condominios cerrados en la medida en que, como lo señala una de las teóricas más perspicaces de la ciudad, la adquisición masiva de propiedades en las principales ciudades por parte de las corporaciones no solo está evitando los intentos públicos de regulación y socavando la capacidad de reclamación de los pobres, sino que, al asignar grandes franjas de espacio y edificios como "un espacio de almacenamiento para el capital”, promueve una desurbanización paradójica de la ciudad (Sassen 2018: 49). Todo esto, según Borja y Carrión, ocurre con el consentimiento y la participación activa de gobiernos locales y nacionales, profesionales urbanos y organizaciones internacionales como el Banco Mundial. En resumen, a medida que los inversionistas, las empresas y los financieros se convierten en los principales actores urbanos que priorizan la acumulación de capital, el gobierno y las organizaciones internacionales emiten discursos piadosos de resiliencia urbana, ciudades inclusivas y desarrollo sostenible, en lugar de reclamar la ciudad en nombre del espacio público, la calidad de vida, servicios adecuados, la sostenibilidad de los territorios y los derechos de los pobres (Borja y Carrión 2017: 50). Como ellos concluyen, "sin control público y social del uso y el precio del suelo no puede haber una ciudad justa" (40).

Una parte integral de esta condición ha sido la fabricación de un ethos urbano del miedo, concomitante con la securitización y la proliferación de condominios cerrados y globalizados, y de centros comerciales altamente vigilados para las élites y las clases medias. ${ }^{4}$ Este diagnóstico tan grave sugiere la necesidad de una transformación radical de la ciudad; "cuestiona el derecho a la propiedad, no acepta la gestión privada de los bienes comunes y servicios de interés común y se opone al productivismo a costa del medio ambiente, de los recursos básicos y de la calidad de vida..., en favor de los objetivos de igualdad y libertad, de reconocimiento por igual de todos los habitantes de un territorio" (Borja y Carrión

4 La proliferación de centros comerciales estilo norteamericano, o "Malls", y sus profundas consecuencias económicas y culturales, es tratado en el excelente libro de la antropó- 
2017: 52). Para estos urbanistas, la "Nueva Agenda Urbana” firmada por los gobiernos en la Cumbre de Quito constituye un compromiso vacío que no representa los intereses de las personas y las demandas de los movimientos urbanos. Esta conclusión se refleja en el 'Manifiesto de Quito', aprobado por el Foro Alternativo del Hábitat III.

Comenzando con la premisa de que 'las ciudades son creadas por personas' (incluso si se las apropian los cárteles de propietarios y promotores), y destacando el hecho de que las clases populares que más necesitan la ciudad también son las más afectadas negativamente por este orden de cosas, el Manifiesto conceptualiza la producción social de la desigualdad espacial y, a la inversa, aboga por un derecho genuino a la ciudad. La clave para este objetivo es la democratización de los territorios urbanos, basándose en los esfuerzos populares de las bases para viviendas y condiciones de vida dignas. "El derecho a la ciudad", afirma el Manifiesto, "fue una consecuencia de los movimientos populares urbanos, especialmente de las mujeres que defendieron y mejoraron sus hogares y sus entornos en su deseo de seguridad y acceso a la educación, el saneamiento y la salud. La ciudad será acogedora y solidaria si se vuelve feminista" (Manifiesto 2017: 321). Citando el bien conocido mandato de Lefebvre de que "la revolución será urbana o no lo será” (pág. 315), y apelando a tradiciones progresistas dentro de la historia del urbanismo, como la ciudad igualitaria de Cerdà, el Manifiesto concluye proponiendo el derecho a la ciudad como

loga Arlene Dávila (2016). Es de anotar que estos centros comerciales caen dentro de la categoría de "espacios basura" propuesta por Koolhas (2014). plataforma teórico-política para profesionales y ciudadanos comprometidos con un movimiento de visión hacia el futuro.

Otra fuente excelente sobre las tendencias actuales en los debates urbanos, aunque un poco más conciliadora, es el análisis (en idioma inglés) posterior a Hábitat III coordinado por UN-Hábitat y el académico e intelectual urbano Richard Sennett, con la participación del urbanista catalán Joan Clos, Director Ejecutivo de UN-Hábitat, y con las contribuciones de un plantel de destacados teóricos y practicantes urbanos (incluidos Saskia Sassen y Ricky Burdett; ver UN-Hábitat y Sennett, 2018). Como Sennett y Burdett declaran en el Prefacio (2018: xii), "la Carta de Atenas de 1933 todavía determina las formas genéricas y la organización física de la ciudad del siglo XXI". ${ }^{5}$

Para estos autores, se necesita una visión muy diferente y abierta de la ciudad si los urbanistas buscan enfrentar los desafíos a la gobernanza urbana que plantea el rápido crecimiento urbano, el aumento de las megaciudades, la aceleración de los flujos migratorios y la destrucción de espacios relacionada con el

5 La Carta de Atenas, elaborada en julio de 1933 por las principales figuras del CIAM (Congrès internationaux d'architecutre moderne) después de una reunión de urbanistas en Atenas, fue muy influenciada por Le Corbusier y tuvo la intención de proporcionar pautas para racionalizar la ciudad. Para un recuento interesante de la Carta, vea Sennett (2018a: 74-78). Para Sennett, la Carta entremezclaba el 'modernismo de concreto blanco de Corbusier', con su 'división entre sus buenas ideas visuales y la pobreza de su imaginación social' (75). Basado en el mantra de diseño que 'la forma sigue a la función', la Carta dio como resultado la celebración de la ciudad funcional, ejemplificada de la mejor manera posible por el plan para Brasilia de fines de la década de 1950; influyó tremendamente en el urbanismo cotidiano en muchas partes del mundo, más aún después de haber sido 'bendecida por Harvard' en una conferencia con muchos de los firmantes originales en 1956. 
desarrollo y la devastación ecológica. Se presta atención a problemas como el acceso al agua, entendido como un cuello de botella para una urbanización exitosa, el desplazamiento de residentes pobres causado por las corporaciones, las políticas fiscales y redistributivas, la conversión de la tierra de lo rural a lo urbano y el lugar de los bienes comunes y la democracia en la planificación y el diseño urbano. La conversación final, entre Sennett y Clos, resalta las tensiones entre ver a la ciudad como un sistema abierto que se trata mejor a partir de las acciones de los habitantes desde abajo, y las acciones en los niveles de la política y la gobernanza oficial. Esta es una tensión recurrente en la literatura especializa$\mathrm{da}$, como veremos en el siguiente apartado.

Tal es el contexto, aunque tratado de manera tan esquemática, en el que hablar de una crisis de habitabilidad tiene sentido. De hecho, puede darse el caso de que la "urbanización planetaria" sea el hecho social, económico, ambiental y político más importante del siglo (Amin y Thrift, 2017). Por primera vez en la historia de la humanidad, la mayoría de la población mundial vive en ciudades. Al mismo tiempo, los marcos para tratar con ellos son obsoletos, lo que agrava el problema. Las expresiones de esta aparente aporía abundan. Para Burdett, las "ciudades hoy se están fabricando y rehaciendo a un ritmo más rápido y a mayor escala que nunca. Sin embargo, la forma en que se planifican y diseñan aún se derivan de un modelo ideológico y espacial que, en el mejor de los casos, está desactualizado en ochenta años" (Burdett 2018: 141).

Este anacronismo se ve agravado por el hecho de que, como Clos lo expresara acertadamente, "hemos creado la ciudad, pero no hemos pensado en cómo la ciudad nos está recreando" (Sennett y Clos 2018: 169), haciendo eco de una conciencia emergente dentro de los estudios críticos de diseño que dicen que diseñamos el mundo y el mundo creado de esta manera, nos diseña a su vez, -o, en pocas palabras, siguiendo la acertada fórmula de Anne-Marie Willies, que el diseño diseña (2006). Para Simone y Pieterse, hay una situación sin salida por la cual "los mismos productos y políticas espaciales que deshacen las prácticas duraderas de las viviendas se ofrecen como la cura contra su pérdida" (2017: 6).

¿Dónde encontramos claves alternativas para la ciudad? Esta es la pregunta a explorar en el resto de este artículo. Por ahora, digamos, incluso si la mayoría de los observadores no lo expresan como tal, que la crisis urbana contemporánea es, más allá de la cuestión de los marcos de planificación y diseño obsoletos, una crisis de cierto modo de habitar de espaldas a la Tierra, que se ha ido naturalizando progresivamente a lo largo de los siglos. Tal crisis de habitabilidad apunta a una crisis más profunda, la de la modernidad colonial capitalista heteropatriarcal como el modelo civilizatorio dominante para el mundo globalizado.

\section{EL “GIRO RELACIONAL” EN LOS ESTUDIOS URBANOS}

El giro relacional se puede percibir en los trabajos de algunos de lx teóricxs urbanxs más creativos de hoy, en algunos de cuyos trabajos me apoyo en esta sección. Como señalaré, a pesar de su riqueza, las novedosas lentes de la ciudad que ofrecen estas obras no nos llevan a las puertas del proyecto de reconfiguración ontológica de la ciudad, aunque son esenciales para articularla. Tres libros en particular desarrollan 
el enfoque relacional de la manera más sostenida: Seeing like a City, de Ash Amin y Nigel Thrift (2017); New Urban Worlds. Inhabiting Dissonant Times, por Abdou Maliq Simone y Edgard Pieterse (2017); y La razón neoliberal, de Verónica Gago $(2014)^{6}$. De manera reveladora, Amin y Thrift describen el giro desde un ángulo ontológico, apoyándose en el neologismo maravillosamente descriptivo de Doreen Massey, "throwntogetherness" (la condición humana de estar abocados a relacionarse con otros), que Massey introdujera hace más de una década para resaltar los entramados de los humanos en múltiples relaciones espaciales, exigiendo 'geografías de responsabilidad' con respecto a los lugares y redes en las que todas y todos, a sabiendas o no, participamos de manera ineludible (Massey 2004, 2005). Escuchemos la descripción de Amin y Thrift del giro (2017: 15, 16):

\begin{abstract}
Esta [throwntogetherness] es una ontología de muchos tipos de fuerza gravitatoria yuxtapuesta: redes metabólicas, infraestructuras y formas construidas, sistemas técnicos e instituciones, diversas estructuras de autoridad, poder e
\end{abstract}

\footnotetext{
6 Este no es una reseña sustancial de la literatura, que lxs lectorxs pueden hallar en las obras citadas. Las ideas de Amin, Thrift, Pieterse and Simone se basan en varias décadas de investigación; es un trabajo interdisciplinario que utiliza un amplio espectro de teorías y campos del saber. Está influenciado por teorías de redes, complejidad y auto-organización que concuerdan con una perspectiva de la ciudad en términos de sistemas complejos adaptativos (e.g., Batty 2005; Escobar 2008). Otros nombres asociados con estas tendencias incluyen Ananya Roy, Philip de Boeck, M. Valverde, Michael Batty, K. Easterling, A. Vasudevan, E. Swyngedouw, M. Keika, M. Gandy, y lxs antropólogxs Teresea Caldeira, Aiwah Ong, James Holston, Ravi Sundamra, y Arjun Appadurai. Saskia Sassen, David Harvey, y Richard Sennett son importantes referentes, y Jane Jacobs una precursora influyente.
}

ideas ... Esta ontología ha sido el foco de un giro 'relacional' en los estudios urbanos en los últimos años, imaginando las ciudades como un campo de fuerza combinatoria... La ciudad no se considera reducible a los imperativos de la infraestructura ola superestructura, ni a la dinámica autoorganizadora de un sistema abierto... En cambio, el enfoque relacional se adentra en la dinámica de atracción y repulsión de híbridos de asociación que compiten entre sí, que buscan explícitamente comprender cómo sus "tráficos, intercambios e interacciones" (Ong, 2009, p. 88) mantienen órdenes y jerarquías de poder particulares.

Esta conceptualización se basa en perspectivas no dualistas sobre la producción de lo social y lo real, incluidas aquellas agrupadas bajo las rúbricas de redes, ensamblajes, rizomas y enfoque neo-realistas, neomateriales, posdualistas y perspectivas más que humanas, a veces incluidas en la etiqueta de "el giro ontológico" (ver Escobar 2018a para una revisión). Aplicadas a las ciudades, estas tendencias implican "ver el mundo como una constelación de conjuntos existenciales, cada uno de los cuales requiere ideas, herramientas y sensibilidades que hagan justicia a su propia integridad, en lugar de a una ficción de un método universal estándar u objetivo" (Amin y Thrift 30, 31). El encuadre alternativo emergente está encapsulado hábilmente por la expresión "ver como una ciudad" (Valverde 2011). En juego está el desarrollo de una epistemología aterrizada adecuada a 
la ontología relacional urbana redescubierta, invocando una preocupación por el "murmullo al nivel del suelo" existente en la ciudad (Amin y Thrift 2017: 5). Esto requiere una orientación etnográfica, especialmente convincente en el trabajo realizado en barrios marginales, una especie de etnografía al nivel de la calle, que recuerda al conocido estilo de investigación y activismo urbano de Jane Jacobs en la ciudad de Nueva York.

Desde la perspectiva de esta "ciudad más que humana", poblada por todo tipo de agencias no humanas (Franklin 2017), la atención se desplaza a los entramados de infraestructuras, tecnologías, materiales y seres humanos. Algunos de los nuevos énfasis incluyen la inteligencia distribuida posibilitada por los sistemas sociotécnicos (Forlano 2016); los diversos híbridos de inteligencia urbana y subjetividad social; y la necesidad de permanecer cerca de las redes de relaciones en lugar de privilegiar las teorías de arriba hacia abajo y los modelos derivados por expertos; en otras palabras, la convicción de que ya no existen guías ni mapas de ruta infalibles sino múltiples perspectivas situadas, que requieren métodos de observación e intervención adecuados para la "ontología rizomática" de la ciudad (p. 165). Esto favorece un enfoque experimental, uno que desafía cualquier re/ composición clara, como en las quimeras computacionales encontradas en gran parte de la literatura de ciudades inteligentes.

Esta sensibilidad teórico-etnográfica a las vidas de los grupos urbanos populares quizás por quien haya sido mejor desarrollada es por AbdouMalik Simone. Ya aparecía en un breve libro poco conocido sobre "el arte de la micropolítica africana” (Hecht y Simone, 1994), centrado en la recursividad y las tácticas de supervivencia populares en las ciudades de África occidental. Una cita del escritor sudanés Abu Gassim Goor que dice que "en África nada funciona, pero que todo es posible" (p. 52), una inversión fantástica que intenta hacer que las personas cambien radicalmente sus imaginarios sobre África, establece el tono vívido del libro, como una especie de etnografía filosófica, impulsada tanto por la teoría como por la observación atenta y cuidadosa de las tácticas locales. Veinticinco años más tarde y muchos proyectos empíricos y aplicados más tarde, Simone y Peiterse cristalizan su enfoque relacional en su tomo descriptivamente titulado, Nuevos Mundos Urbanos. Como los mundos mismos, en su opinión, son nuevas las formas en que los teóricos los perciben. El enfoque es decididamente etnográfico, privilegiando la mentalidad y las prácticas de los habitantes urbanos, particularmente en Asia y África. La complexión hechiza de estas ciudades, en su opinión, requiere nada menos que un "pragmatismo aterrizado tierra", capaz de expandir dramáticamente recuentos de la relación entre lo social y las ontologías relacionales (Simone y Pieterse 2017: xii)

Su súplica pide enfoques abiertos a la paradoja y a la experimentación, capaces de lidiar con las tensiones entre la incorporación y la digitalización, el apego al lugar y la experiencia con la globalidad, lo ciudadano y lo extranjero, el individuo y la comunidad, el capital global y las fuerzas locales, las estructuras formales $y$ las prácticas informales, las soluciones normativas frente a las singularidades de cada barrio. Habitar estas paradojas, como ellos lo expresan, implica "nuevas imaginaciones políticas del trabajo urbano..., la práctica política de sostener una doble visión que afirma la importancia 
de experimentos simultáneos en los niveles de la vida cotidiana y en los mundos de la política y la gobernanza oficial" (9).

Para este fin, delinean un marco basado en tres intervenciones conceptuales: re-descripción, o reencuadrar y visualizar lo urbano de otra manera, identificando lo que podría constituir una ocasión para la experimentación basada en las vitalidades locales; la secreción, o la atención a las formas como aquello que es capturado por el valor del capital también se le escapa, cómo se ejerce el poder pero también cómo se secreta a través de las infraestructuras, como en las reparaciones improvisadas practicadas por personas en tantos barrios pobres del mundo; y la resonancia, en relación con los intentos de la gente de aprovisionar agua, alimentos, energía y trabajo conectándose entre sí a través de "intervenciones acupunturales" y un recoger que resulta de los modos en que las personas, la información y las cosas "se extienden mutuamente"(P. 17). En lugar de una visión de los pobres como objetivos para la redención o la reforma a través de políticas públicas y de "formulaciones algorítmicas" (20), estos conceptos dirigen la atención al juego del afecto, la inteligencia de la calle y la acción colectiva en red. Es desde esta perspectiva (informada por su propia marca de análisis dialéctico, postestructuralista y fenomenológico) que llegan a un enfoque de la ciudad que escapa a las dicotomías de tipo "esto/o aquello (28-30):

Los esfuerzos para abordar estos problemas requieren sensibilidad, conocimiento e intervenciones, tanto a escala molecular como macro-política. Requiere un respeto por cómo se hacen las cosas en sus propios términos, sin abandonar un compromiso ético de cómo las cosas también podrían funcionar de manera diferente. Las intervenciones políticas urbanas deben tener en cuenta simultáneamente las estructuras formales de gobierno y las movilizaciones de resistencia de los insurgentes, tanto la esfera pública como los terrenos íntimos de las prácticas locales y la habitabilidad... [Esta perspectiva] implica un repertorio político ampliado que puede acomodar y respetar políticas insurgentes compuestas tanto de de resistencias militantes como de actividades de desarrollo prefigurativo que permitan atender a los imperativos urgentes de los medios de sustento.

Al ver a la ciudad como 'un conjunto de cinco sistemas operativos desarticulados" (infraestructura, economía, tierra, gobierno y sistemas culturales), Simone y Pieterse examinan las resonancias entre ellos, analizan diversos escenarios de políticas urbanas, deconstruyen la base de muchas cuantificaciones paramétricas, la planificación y la arquitectura subyacentes en la "carrera hacia la construcción" especulativa en ciudades asiáticas y africanas, y reconceptualizan las articulaciones entre las improvisaciones cotidianas y los movimientos sociales urbanos. La base de su análisis, sin embargo, es la multiplicidad de prácticas populares que a menudo surgen del hecho simple de que la ciudad no funciona de acuerdo con el plan (183).

El compromiso de mantener estas historias en juego, en lugar de explicarlas a través 
de discursos teóricos totalizantes, es altamente recomendable, y es un antídoto muy necesario contra la tendencia desarrollista de traducir estas historias a narraciones universalistas. Podríamos concluir que, para ellos, el giro relacional es "sobre la política de cómo contar historias, para proveer a los diferentes tipos de actores con narrativas a través de las cuales pueden encontrar trayectorias que los acerquen" (188). En resumen, se trata de un trabajo de ensamblaje que adopta una política de diferencia que contrarresta la política de indiferencia y falta de respeto que enfrentan los pobres de las zonas urbanas día a día cuando se aventuran fuera de sus barrios "informales" hacia las ciudades "formales".

Encontramos la orientación etnográfica y relacional en el excelente libro de la socióloga argentina Verónica Gago (2014). La obra muestra cómo los llamados sectores informales sobrepasan su determinación desde arriba, al mismo tiempo que son profundamente afectados y a veces explotados desde allí. Tomando el inmenso y próspero mercado "ilegal" en las afueras de Buenos Aires conocido como La Salada como punto de partida, Gago desarrolla una novedosa conceptualización de las economías populares que han florecido en muchos espacios urbanos durante la era neoliberal. Demuestra cómo, aunque uno de los principales rasgos de estas economías es sin duda una nueva forma de racionalidad calculadora, dicha racionalidad está lejos de conformarse a las demandas del celebrado homo oeconomicus de la filosofía liberal. De hecho, enactúa un pragmatismo vital que nutre sin cesar nuevas configuraciones de vida social. Su etnografía revela la tensa mezcla entre cálculo y libertad, obediencia y resistencia, individualismo y comunidad, y autonomía y sometimiento que alimenta a los sectores populares del Sur Global.

Al mismo tiempo, la autora despliega las potentes nociones alternativas de progreso y bienestar que surgen de estos entramados populares; más que lógicas modernas de acumulación, dichas nociones no-métricas celebran la capacidad de la gente para preservar, y a veces aumentar, sus territorios de diferencia cuando se ven forzadas a navegar las fuerzas del despojo ejercidas sobre ellas despiadadamente por el capitalismo global y los estados-nación. El resultado son abigarradas "comunidades neotrasnacionales" que se deleitan en sus mezclas en vez de esforzarse por mantenerse puras, pero que igualmente evidencian intensos momentos comunitarios a través de festivales y celebraciones donde aún se pueden escuchar ecos de pasados distantes pero revitalizados. En las ferias, de este modo, se encuentra una vitalidad pragmática, desplegada por ejemplo en la verdad ineludible de las ubicuas "copias falsas" sin originales (los "Nokia”, "Nikes" y "Chanels" encontradas en tantos puestos de venta de las ferias informales), el hecho social improbable pero real de dinámicos entramados sin reglas fijas. Al re-teorizar estos contextos comunales, Gago apunta a la existencia de subjetividades poscoloniales así como a ingeniosas reinvenciones de la modernidad. Demuestra que lo que está en juego en estos espacios urbanos son configuraciones socio-culturales inéditas donde aparecen regímenes particulares culturales de persona y comunidad, los cuales quizás adquieren cierta estabilidad, así sea de manera algo precaria. 
Para resumir algunas de las características del enfoque relacional, y agregar algunas otras: existe una indudable sensibilidad etnográfica, a menudo explícitamente política cuando se une con el compromiso de ver la ciudad desde "los espacios de los destrozados" (Fry 2017: 80), o los espacios de los expulsados (Sassen 2014). En relación con esto, existe un compromiso de unir la crítica con el pensamiento pragmático políticamente informado sobre las posibles intervenciones desde abajo, pero también desde los espacios de políticas sociales y diseño. Estas intervenciones se imaginan a través de una comprensión renovada de la complejidad urbana que solo las investigaciones sobre el terreno pueden proporcionar. La arquitectura, la planificación urbana, o el diseño urbano se encuentran a menudo deficientes, cuando no son cómplices de las agendas de los gobiernos, vinculadas a la valorización capitalista del espacio urbano. Además, muchos autores dan por sentado el final de la ciudad modernista europea como modelo, con la ausencia concomitante de cualquier modelo o plano único. La atención a la materialidad a menudo está presente, ya sea a través del interés en las dimensiones más que humanas de la ciudad, el metabolismo urbano en aumento exponencial, los sistemas sociotécnicos o la preocupación por el cambio climático y el Antropoceno. Finalmente, hoy existe un cierto consenso de que, a pesar de la importancia crucial de las ciudades en la actualidad y de lo ineludible de la urbanización planetaria, gran parte de la ciudad se encuentra en ruinas, y tendrá que replantearse, reconfigurarse y rehacerse significativamente.

Aun así, y a pesar de la atención a lo no humano, la cuestión de la interdependencia radical entre todo lo que existe, vivo o no, sigue siendo esquiva en estas obras. Bien podría ser que las ciudades, por definición, nunca podrán llegar a acatar este principio onto-epistémico de existencia y de sentido común, dada su dependencia de infraestructuras complejas, altas densidades de seres humanos y materiales, vastas huellas ecológicas y una demanda energética cada vez mayor. Sin embargo, antes de rendirnos, quizás de manera prematura, ante esta posibilidad, me gustaría presentar un valiente intento de hacer de los enfoques relacionales radicales una opción tangible. $\mathrm{Me}$ refiero a la propuesta de una nueva fusión entre campo y ciudad por el arquitecto y diseñador de la Universidad del Valle en Cali, Colombia, Harold Martínez Espinal.

\section{III. ¿UNA NUEVA “FUSIÓN” ENTRE CAMPO Y CIUDAD? LA GEOFILOSOFÍA DE HAROLD MARTÍNEZ}

La marginación sistemática de las formas de ser, saber y hacer de los campesinos es la premisa inicial para el arquitecto de la Universidad del Valle en Cali, Colombia Harold Martínez Espinal (2013, 2016; e Iglesias y Ortiz 2016 para un estudio del trabajo de arquitectura y diseño de Martínez). Su propuesta de "una nueva fusión de campo y ciudad" se basa en una perspectiva profundamente relacional y puede fomentar formas alternativas de urbanismo. Su punto de partida explícito es una conceptualización sostenida de lo que él ve como una crisis de habitabilidad derivada de los "modos de vivienda occidentales" (dentro de los cuales también se ubica en América Latina urbana). "Después de toda la euforia sobre la modernidad, el progreso y la globalización", afirma, "el ser humano 
occidental comienza a percibir por primera vez, aunque de manera fragmentada, el colapso de su paradigma civilizatorio y su catastrófico contexto social, económico y social, y especialmente, sus consecuencias ecológicas"(2016: 13).?

El corolario de este diagnóstico es la necesidad de volver a formas de habitabilidad compatibles con la complejidad de la vida, por lo que introduce una serie de conceptos: la termodicidad de la materia ("termodicidad", definida por la entropía del universo); "interacciones asociativas", es decir, el conjunto de relaciones involucradas en la creación de todas las formas de vida y procesos (otra forma de nombrar la relacionalidad radical); y hábito, hábitat y habitabilidad. El hábito se refiere al espíritu de la materia, es decir, la capacidad de la vida para las interacciones asociativas; hábitat, junto con la ecología de sistemas, a las redes de formas de vida, pero también a "la singularidad alcanzada por un territorio a lo largo del tiempo", gracias a la interacción entre lo vivo y lo no vivo (2013: 151); y habitar, a la interacción recursiva entre las entidades vivientes y sus entornos para garantizar su bienestar. ${ }^{8}$

7 A lo largo de su trabajo, Martínez teje, de una manera muy original, elementos de su práctica arquitectónica y de diseño con fuentes muy eclécticas de la filosofía, la teoría social y la biología teórica. Para comenzar con lo último, incluyen teorías de autopoiesis, autoorganización, complejidad y emergencia, en términos generales; fenomenología; Filosofía política (Marx, Vattimo, Deleuze y Guattari); y críticas de la sociedad industrial avanzada (la Escuela de Frankfurt, Illich). Aunque reconoce su aprendizaje dentro del canon arquitectónico occidental, lo relee críticamente ('esa devoción y peregrinación eurocéntrica que la civilización occidental exige a todos los que practicamos la bella profesión de la arquitectura', desde Miguel Ángel hasta Le Corbusier y Gehry; 2013: 12). Una fuente importante fueron sus viajes a través de tradiciones arquitectónicas no occidentales.

8 Por motivos de espacio, no trataré aquí otros conceptos,
Estos conceptos constituyen la base para repensar "la existencia de todo ente como espacialmente sistémicas" (p.18), que élentiende en términos de autopoiesis o autocreación. La vida es el resultado de un proceso comunitario de simbiogénesis y reciprocidad, en curso desde los albores del planeta, que eventualmente creó las condiciones para la habitabilidad humana terrestre. Durante la mayor parte de su historia, los humanos pudieron practicar modos de vivienda en sintonía con el carácter autoorganizado de la vida; comenzó a romperse con el diseño geométrico y el antropocentrismo de la polis griega, que marcó el inicio del largo viaje civilizatorio de Occidente hacia una ontología de separación del mundo natural. El hábitat se convirtió en el fondo discreto de la saga humana. Gran parte de lo que vemos en las ciudades de hoy encuentra su larga genealogía en esta ascendencia del antropos y del logos y su desarrollo constante a través de la cultura heteropatriarcal occidental.

Uno puede anticipar el proyecto de Martínez basado en estas premisas. "Habitar", sostiene, "es interactuar con el mundo de los hábitats donde todo fluye de manera asociativa" (2016: 187). Se aventura a posicionar la habitabilidad como "la categoría central para organizar la complejidad del pensamiento humano" (2013: 20). Recuperar nuestra capacidad de habitabilidad terrestre requiere, en términos filosóficos, una nueva forma de ser en el mundo que él define, haciéndose eco de Heidegger, como ser-al-estar-en el mundo y el lugar, superando la forma desencarnada y descontextualizada de ser creada a lo largo

como salubridad, comodidad y ludicidad (salubridad, confort y lo lúdico), que Martínez plantea como condiciones necesarias para una noción renovada de vivienda. 
de la historia occidental. Además de esta ontología de separación de la cultura occidental, Martínez presta especial atención a la creación de espacialidades que van en contra del mundo natural por la urbanización capitalista y la manera en que han intensificado el antagonismo entre el campo y la ciudad. La creación de otras formas de vivienda implicaría conlleva diseños en los cuales "solo será posible seguir siendo y estando, mediante hábitos colectivos, en ciudades donde lo urbano se fusiona como ente colectivo con su hábitat natural, que por esencia ya sabemos, es un ente colectivo. Ciudades donde los humanos solo podrán ser, como los demás seres vivientes, simplemente ocupantes de un suelo vivo al que le deben un ethos de reciprocidad y complementariedad y más específicamente, de interacción asociativa" (2016: 22).

Durante la última década, Martínez ha desarrollado una serie de diseños que dan contenido a sus ideas. Si bien ninguno ha sido construido como un prototipo todavía, vale la pena considerarlos aquí. La idea fundamental para este ejercicio de imaginación de diseño es que la tierra se nutre de "la fuerza verde del suelo", por lo que significa la dependencia de la vida de la fotosíntesis y el mundo vegetal. Desde aquí propone "una nueva fusión entre campo y ciudad", que se realizará a través de diseños que incorporan modos de vivienda campesinos. Sus dibujos y modelos preliminares incluyen apartamentos de unos 60 metros cuadrados dispuestos en edificios de dos a cuatro pisos (el tamaño actual de las viviendas subvencionadas por el gobierno en Colombia), con corredores equipados con estantes móviles para plantar alimentos (verduras, hierbas y otras plantas), y rodeado de huertas y zonas verdes. La idea es establecer una circulación "desde el jardín al corredor y de aquí a la cocina y la mesa del comedor". Más que un vestíbulo estéril de clase media, el piso de entrada funcionaría como un centro social y un lugar de reunión. El objetivo del diseño es introducir una visión campesina de la tierra en la ciudad, reconstituyendo el edificio de apartamentos y el vecindario como lo que podría llamarse territorios rurbanos. Al imponer la reciprocidad entre el espacio construido y los espacios de alimentos/verdes (en términos de superficie), surgiría una ciudad que integra la fuerza verde del suelo dentro del paisaje urbano. Martínez prevé plantar estos edificios, que realmente existen entre el campo y la ciudad, en áreas urbanas a través de unidades habitacionales de 800 personas en edificios de dos pisos, o el doble en unidades de cuatro pisos, y eventualmente una red de dichos edificios que conforman barrios de cerca de 10000 personas. $^{9}$

La visión de Martínez se basa en la noción de que la vida sucede en el espacio y el territorio; tiene un lado colectivo decidido, ya que "habitar es vivir en comunidad, creando y manteniendo un entorno" (2013: 156). Tal como él lo ve, el objetivo del diseño implica "un lenguaje arquitectónico novedoso, capaz de llevar a cabo una interacción asociativa amorosa con los paisajes naturales" (p. 21). Al vincular

9 Esta presentación rápida del modelo en evolución de Martínez se basa en numerosas conversaciones con él en Cali (2016-2018), así como en su detallada presentación en power point y bocetos del modelo. Fue a partir de estas conversaciones que comencé a pensar acerca de la rurbanización y el re-equipamiento ontológico. Me sorprendió descubrir que el Oxford Living Dictionary tiene una entrada para la rurbanización ("La influencia de la sociedad rural en la vida urbana, o viceversa; urbanización rural"; https://en.oxforddictionaries.com/definition/rurbanization, accesible 21 de junio de 2018). También encontré una publicación interesante ( $\sin$ fecha, titulada o nombrada) en internet sobre la rurbanización en la India, definida como 
la habitabilidad, el diseño, la vida, el espacio, la crisis, la ontología (relación) y, en última instancia, la ética y el cuidado, él articula un marco convincente para la dimensión urbana de las transiciones al pluriverso. Después de una larga prehistoria de habitabilidad biocéntrica, seguida de veintiséis siglos de antropocentrismo, podría llegar, argumenta, a una era genuinamente geocéntrica.

La posición política de Martínez es la de un eco-socialista autoproclamado, que reconoce la alienación de los demás seres humanos y el mundo natural por parte del capitalismo, para corregirla a través de la ética de la interacción asociativa que es la esencia de toda vida. Debido a que tiene una lógica comunitaria e integradora incorporada, la habitabilidad debe excluir los privilegios (2013: 152). Al ver al humano como el habitante de un universo viviente, en lugar de ser un ocupante de un suelo pasivo, se mueve decididamente hacia una concepción postdualista de la vida socionatural, en sintonía con las perspectivas "más que humanas" de hoy. Su marco constituye una praxis arquitectónica para las transiciones, puesta al servicio de toda la vida y basada en un compromiso renovado con un humano "para quien la ética y la estética provienen del significado más profundo de la vida misma" (2013: 49). Finalmente, se podría decir que Martínez también es un ejemplo de pensamiento decolonial, y no solo por su crítica del progreso y la modernidad. En términos arquitectónicos, a medida que viajaba a través de tradiciones arquitectónicas

\footnotetext{
"un proceso de alteración de formas rurales con patrones y estilos de vida urbanos preseleccionados, que crea nuevas formas de lo rurban modificadas genéticamente." http:// sdmahajan.tripod.com/rurbanization.htm, consultado el 21 de junio de 2018.
}

vernáculas más allá de Occidente, incluidas las de los pueblos indígenas de las Américas, practicó un "descentramiento cultural de Occidente” (2013: 13). Además, avizora una posible reconstitución de "una nueva época en la identidad latinoamericana donde se empieza a reconocer que el valor de su historia no radica en la invasión europea en el siglo XV [ni en la ruta de la Modernización, el Desarrollo y la Globalización] sino que ésta comienza realmente hace unos 12.000 años con los pueblos originarios que han sabido resistir los últimos 500 años de opresión y exterminio, protegiendo, disfrutando y conservando el hábito de la interacción asociativa" (2016: 196). ${ }^{10}$

Quisiera añadir unas palabras sobre la relevancia del heteropatriarcado a $\mathrm{mi}$ argumento. Ninguno de los autores hasta ahora identifica al patriarcado como algo central en la crisis urbana. El enlace aún está por hacerse. Como lo sugieren varios escritos feministas fuera del núcleo del mundo académico angloamericano, el patriarcado conlleva la erosión sistemática del fundamento relacional de la vida. La invasión de las culturas patriarcales, que comenzó en Europa hace varios miles de años, no ha dejado de afianzarse en la mayoría de las sociedades. Para las feministas decoloniales latinoamericanas, con la Conquista de América, los "patriarcados de baja intensidad" de los mundos comunales indígenas dieron paso al "patriarcado de alta intensidad" de la modernidad capitalista (Segato 2016). Estas investigadoras caracterizan las culturas matriarcales y patriarcales como diferentes

10 Habría muchos temas que discutir sobre la propuesta de Martínez, incluida la articulación entre la ciudad y la agricultura y la agroecología apropiada para sus unidades. 
maneras de vivir, relacionarse y emocionar (por ejemplo, Maturana y Verden-Zöller 2008; von Werlhof 2011). Las culturas patriarcales valoran la competencia, las jerarquías, el poder, el crecimiento, la apropiación, la procreación, la negación de los demás, la violencia y la guerra. En estas culturas, los humanos modernos buscan la certeza a través del control, incluido el control del mundo natural. Por el contrario, las culturas matrísticas históricas se caracterizaron por conversaciones que destacaban la inclusión, la participación, la colaboración, el respeto, la sacralidad y la renovación cíclica siempre recurrente de la vida. Ellas requerían ser conscientes de la interconexión de toda la existencia.

Hay formas de ser no heteropatriarcales, incluidas prácticas de género no binarias, disponibles en la historia, y muchas otras tendrán que ser inventadas. Lo que está en juego es toda una política para otra civilización que respete y se fundamente en la interconexión radical de todo lo vivo, lo que la socióloga feminista mexicana Raquel Gutiérrez Aguilar (2017) llama política en femenino, centrada en la reproducción de la vida, en conjunto con la reapropiación de bienes producidos colectivamente (postcapitalismo), y más allá de los cánones masculinistas de lo político, vinculados al capital y al estado. Para la antropóloga argentina Rita Segato (2016), esta sería una política que ponga fin a la "minorización" de las mujeres que ha acompañado a la descomunalización de los mundos modernos, a favor de una política autónoma de re-comunalización que restaure la 'plenitud ontológica' de los mundos de las mujeres. Re-tejer el tejido comunal y relacional de la vida significa, como ella dice, que "la estrategia, desde ahora propia, es femenina'
(106). Si bien no puedo profundizar en estos aspectos de decisiva importancia para el proyecto de terraformar la ciudad en este artículo, creo que son caminos cruciales que deben seguirse. ${ }^{11}$

\section{LA PERSPECTIVA DEL DISEÑO ONTOLÓGICO}

Ya nos encontramos con las nociones de ontologías dualistas y relacionales como una estrategia heurística para transmitir las diversas formas de ser en el mundo, en el espacio y el territorio. La relación entre el diseño y la ontología es menos evidente, pero existe un enfoque emergente, el diseño ontológico, que surge de esta relación (Fry 2012, 2017; Escobar 2018a). La instanciación más reciente de esta tendencia es su aplicación a las ciudades, sobre todo por Fry (2017). Fry centra este proyecto en el concepto de metroffiting o reequipamiento ontológico, un marco orientado ontológicamente para repensar y rehacer ciudades después del agotamiento de la ciudad europea como paradigma de diseño. En este artículo solo podré presentar un esbozo de la propuesta de Fry.

El punto de partida de Fry es el efecto ontológico de desfuturización del diseño moderno, lo que implica la creación del diseño de un mundo-dentro-del-mundo de

11 Algunos de los estudiosos en cuestión incluyen a Claudia von Werlhof, Maria Mies, Veronica Bennholdt-Thomsen y Silvia Federici en Europa; Vandana Shiva; las australianas Val Plumwood, Ariel Salleh y Wendy Harcourt; y un grupo importante de feministas latinoamericanas decoloniales, negras e indígenas. Examino estas obras en un libro reciente (2018) y en un comentario para un debate patrocinado por la Gran Iniciativa de Transición, http://greattransition. org/roundtable/feminism-revolution-arturo-escobar (consultado el 21 de junio de 2018). 
insostenibilidad estructurada que resulta en el Antropoceno. Como respuesta, postula un movimiento de reparación hacia lo que denomina 'Sostenimento', un proceso que reconoce la dialéctica de la creación y la destrucción integrales a la acción humana, y que al hacerlo podría mover a los humanos hacia una ética de cooperación y convivencia en la diferencia. Este es el trasfondo para el reequipamiento ontológico (2017: 16, 17):

$\mathrm{Si}$, como es el caso, la humanidad tiene que cambiar de manera adaptativa para poder sobrevivir, entonces tiene que haber entornos ontológicamente de diseño que estimulen y apoyen este proceso... La agenda de metroffiting comienza a adquirir un poco más de forma. Como tal, tiene que explorar la indeterminación de la ciudad, su fragmentación, sus fronteras porosas, su metabolismo creativo y destructivo, los riesgos a los que está expuesta, lo que debe aprenderse, lo que puede repararse y quién lo puede reparar. La política del cambio, y el imperativo de actuar en el tiempo. ... [En suma] la reconfiguración de las ciudades, como acción y resultado, es un medio de nuestra propia remodelación" (17).

Por lo tanto, el reequipamiento o reconfiguración urbana adquiere una dimensión ontológica: la reconstrucción de la ciudad sobre la base de los mundos relacionales de los que depende la vida. Los muchos intentos de ecologizar la ciudad, según su punto de vista, aunque tienen algún mérito, pero no van lo suficientemente lejos. Es esencial ver la ciudad como un evento de diseño cargado de complejidad histórica, que es, al mismo tiempo, un evento metabólico con el que debe comprometerse el reequipamiento ontológico. Es imperativo reconocer que "la reconstrucción de la ciudad se encuentra en su deshacerse" (p. 112). Pero esto debe hacerse con criterios ontológicos claros (pág. 123):

$$
\begin{aligned}
& \text { Entonces, ¿qué hay que } \\
& \text { enfrentar? La respuesta más } \\
& \text { general y desalentadora es, } \\
& \text { como se dijo, el desafío de la } \\
& \text { transformación ontológica } \\
& \text { de nuestro ser en el mundo... } \\
& \text { Aunque astronómicamente } \\
& \text { difíciles, se pueden contemplar } \\
& \text { transformaciones significativas } \\
& \text { mediante un ejercicio masivo de } \\
& \text { diseñoontológico... Enlugardeestar } \\
& \text { en oposición a la sostenibilidad, } \\
& \text { se necesita una estrategia de } \\
& \text { cambio mucho más sustancial y } \\
& \text { fundamental en la que el diseño } \\
& \text { y reequipamiento ontológico son } \\
& \text { elementales, una meta basada } \\
& \text { en el proyecto y el proceso del } \\
& \text { Sostenimento (ya registrado } \\
& \text { como un proceso teóricamente } \\
& \text { informado entendido como un } \\
& \text { proyecto posterior a la Ilustración } \\
& \text { de una escala tan grande o mayor } \\
& \text { quela Ilustración). }
\end{aligned}
$$

Fry se refiere al encuadre resultante como 'post-sostenibilidad' y como una "recreación fundacional" (palingenesia), un renacimiento a partir de las ruinas de la ciudad (2017: 135; 2012). Una serie de procesos históricos 
constituyen tanto el mayor desafío como las condiciones de posibilidad para esta refundación y reconstrucción: la reubicación masiva de personas desplazadas por conflictos ambientales; conflictos inducidos por el clima; la necesidad de mover ciudades en riesgo; y la creación de nuevas ciudades en el contexto de todo lo anterior (véase también Fry 2015). La renovación de la planificación y el diseño en dominios como la energía renovable, la alimentación urbana, el transporte, la gestión de los residuos biológicos, la calidad del aire y del agua, la vivienda, etc., se volverán esenciales para esta tarea, a fin de restablecer algún tipo de equilibrio biofísico para la vida urbana. La política tiene que ser relacional. Para citar a Fry por última vez, "una comprensión ontológica afirmativa del diseño, como base del reequipamiento ontológico, puede ser mucho más comprometida relacionalmente y dinámica [que el diseño modernista instrumental] en la creación de disposiciones situadas diferencialmente para nuestro ser en el mundo. Una que sea menos destructiva”. (P. 145).

Habría muchos otros aspectos para discutir de la visión de Fry, como su crítica del posturbanismo como una abdicación por parte de los arquitectos de su responsabilidad por la ciudad; su sensibilidad poscolonial y su llamado para un diseño para y con el Sur Global, más allá de "un eurocentrismo hegemónico y oculocéntrico, con su forma dominante de conocer" (94); y su decidido apoyarse en la convivencia (haciéndose eco de Ivan Illich), lo que le permite tomar una posición en contra de las tan cacareadas soluciones tecnológicas patriarcales que plagan los imaginarios del futuro. Por ahora, en la última parte, quiero volver a la discusión sobre el terraformado de la tierra mediante la introducción de tres elementos finales de análisis: la visión de Ananya Roy de la interfaz rural-urbana, que ayuda a reforzar el proyecto de Martínez; el marco de las ciudades biofílicas de Timothy Beatley para integrar la naturaleza en el diseño y la planificación urbana, que se acerca más al enfoque relacional de este artículo, y las nociones de la autonomía y lo comunal del campo de las luchas territoriales, que pueden contribuir a infundir la rurbanización y el reequipamiento con un sentido explícito de la política.

\section{LAS NATURALEZAS URBANAS, LA AUTONOMÍA Y LO COMUNAL}

Para empezar con Roy: ¿Qué significa "lo urbano" en los estudios urbanos críticos? Esto es lo que ella pregunta. Roy tiene razón al señalar cierto urbanocentrismo en este campo, de dos maneras: la noción dada por descontado de "la urbanización de todo", dada la mera importancia social y económica de la ciudad (por ejemplo, las megaciudades, que se toman como representación ineludible de la urbanización global); y nociones naturalizadas de lo urbano en la teoría actual en la geografía y los estudios urbanos. Aborda estos temas desde una perspectiva reveladora, al plantear que "lo rural” es un afuera constitutivo de lo urbano. Quiere que devolvamos a estos términos su historicidad, particularmente cómo han funcionado como categorías gubernamentales, para revisar, con la ayuda del trabajo empírico en ciertas interfaces rural-urbanas, la cuestión de qué se considera urbano. Me interesa lo que suceda con lo rural al realizar esta operación, y si la rurbanización gana algo de valencia desde esta perspectiva. 
La deconstrucción de Roy de la polaridad rural/urbano comienza por cuestionar la reducción de lo rural a lo no urbano. Históricamente hablando, lo rural y lo urbano estaban entreverados, como lo ejemplifica el caso de la India. Esto se debía tanto a los vínculos sociales existentes entre poblaciones y sus materialidades como a las categorías gubernamentales, incluso si lo rural y lo urbano a menudo se han mantenido separadas por sus respectivos campos de estudio. Lo que ella encuentra en muchos sitios que experimentan una supuesta urbanización no es lo que la teoría urbana crítica podría predecir: la expansión de las redes, las expulsiones, la conformación de identidades y movimientos urbanos. "Los lugares cuyas historias estoy tratando de contar", dice ella, "no pueden entenderse como geografías de la urbanización"' (2016: 819). Si bien reconoce que lo urbano es una multiplicidad ontológica, también lee en ello formas y prácticas rurales distintivas, ciertamente no todas liberadoras pero tampoco conformes con guiones urbanos preestablecidos. Lo que ella reclama es debilitar el efecto de las teorías totalizantes para percibir de nuevo las diferencias históricas y los factores indecidibles.

Roy termina su análisis con la declaración en una placa en la entrada de uno de los panchayats o aldeas que estudió, que contiene una frase de un poeta de finales del siglo XIX sobre "un hermoso Bengala que se considera rural y verde" (822). Como ella concluye, y a pesar de la indudable prominencia de la modernidad urbana india, esta placa "se puede leer como una anticipación y premonición fortuita de lo urbano que estaría por venir, pero su ruralidad no se puede borrar o eliminar" (822; nuestras, las cursivas).
La reflexión de Roy me permite reflexionar sobre si los prototipos rurbanos de Martínez -y el reequipamiento ontológico material y epistémico más amplio que requerirían- podrían encontrar una condición propicia de posibilidad en aquellos espacios donde "lo rural" aún está vivo y quizás ocasionalmente prosperando dentro de "lo urbano", así no fuera siempre reverdeciéndose. Encuentro apoyo para esta idea en el incipiente campo del diseño y la planificación urbanos biofílicos (Beatley 2011; 2016). No necesitamos estar de acuerdo con la fuente de Beatley para su tesis, a saber, la creencia del biólogo E. O. Wilson en la existencia de una inclinación emocional innata de los humanos hacia los otros seres vivos, para apreciar su visión. Reconocer las múltiples entidades vivientes presentes en la ciudad es solo el punto de partida hacia el urbanismo biofílico. Si bien puede utilizar elementos del urbanismo verde, va mucho más allá para involucrar el reverdecimiento sustancial de infraestructuras, actividades, actitudes y conocimientos, e instituciones y gobierno. De manera sucinta, las ciudades biofílicas son lugares profusamente dotados de naturaleza fácilmente accesible y abundante, capaces de atraer a los residentes a la integración con la naturaleza a través de entornos multisensoriales, a veces imitando a la naturaleza. El diseño biofílico apunta a un metabolismo urbano sostenible basado en filosofías de circuito cerrado, participa activamente en el bioregionalismo y la restauración ecológica, y reimagina las ciudades como entidades que albergan formas naturales. Todos estos elementos están pensados en los niveles de vivienda, manzana, calle, vecindario, comunidad y región. 
Incluso los intersticios y el pavimento excesivo pueden proporcionar un medio para volver a terraformar la ciudad, incluso para la agricultura urbana (tales como el ejemplo de Detroit o las nuevas "supermanzanas" en Barcelona). Los ejemplos abundan y engalanan las páginas del libro y del manual complementario. ${ }^{12}$

La mayoría de los ejemplos de Beatley's provienen del Norte, lo que sugiere la importancia de los enfoques de diseño del Sur, que reflejan tendencias más amplias que incluyen la descolonización del diseño, el diseño decolonial, los diseños del Sur y el diseño autónomo (ver Escobar 2018b para una revisión). Beatley conserva una cierta noción naturalizada de la naturaleza como algo separado de los humanos, y de este modo su propuesta va solo a mitad de camino hacia la reconversión de proyectos basados en la interdependencia radical. No obstante, su enfoque deja en claro que hay más en juego en terraformar que los techos verdes, los parques urbanos e incluso las ciudades sostenibles. La mayoría de los defensores de las ciudades sostenibles permanecen dentro de un marco modernista de políticas de gestión, incluso cuando están conscientes de esta limitación (por ejemplo, Cohen 2018). Hay, por supuesto, intentos muy interesantes para traer de vuelta lo natural a la teorización de la ciudad, como aquellos en cuanto al queerying de la ciudad (Gandy 2012), las llamadas ecologías emergentes (Kirskey 2015) y formas emergentes de vida en los intersticios de las ruinas dejadas por el capitalismo (Tsing 2015), y materialidades vibrantes, urbanas o de otros tipos (Bennett 2011). Si bien la discusión de estas tendencias está más allá del alcance de este

12 Adopto el término 'terraformar' de Beatley (2011: 104), aunque lo tomo de forma ontológica explícita. artículo, es un reflejo de la necesidad de que los estudios urbanos aborden en serio la cuestión de lo no humano dentro del contexto específico de las ciudades. Resuenan con lo que he llamado en este artículo, terraformar, es decir, volver a imaginar las ciudades como entidades vivientes a través del reequipamiento ontológico. ${ }^{13}$

Debo agregar que no he tratado aquí con los antecesores históricos del ecologismo urbano, como el movimiento de las Ciudades Jardín o, incluso antes, las ideas de mutualidad que inspiraron a la Comuna de París, y otros movimientos. Tampoco me he referido a la cuestión de que las ciudades siempre han sido entramados "más-quehumanos", a pesar del discurso predominante de las ciudades como "ciudadelas humanas" diseñadas contra la naturaleza (Franklin 2017). El giro relacional está haciendo mucho para revertir esta visión. El descentramiento de lo humano en el diseño urbano (Forlano 2016, 2017) está generando un rico conjunto de perspectivas no-antropocéntricas, al considerar lo vivo ("naturaleza"; animales, plantas, microorganismos) y lo no vivo (por ejemplo, lo digital y socio técnico). Al proliferar la agencia de lo no humano, y al celebrar

13 Es necesario que haya más puentes entre las tendencias en los estudios urbanos que describí en este documento y los debates en geografía con las geografías "más que humanas" e híbridas, como en las importantes obras de Sarah Whatmore, Bruce Braun y Noel Crastree. Estos temas son importantes en la ecología política antropológica y geográfica, y no reciben la atención que merecen en los estudios urbanos críticos. Algo similar puede decirse de la antropología urbana, particularmente su atención a la relación entre la teoría y la etnografía urbana, incluida la reflexión sobre categorías como la espacialidad, la comunidad, los mercados, la solidaridad, los bienes comunes y las divisiones sociales en términos de raza, clase y sexualidad. Véase el útil volumen del estado del arte sobre antropología urbana editado por Don Nonini (2014). 
las posibilidades políticas de la agencia distribuida, sin embargo, me parece que puede haber un aplanamiento de la agencia donde se combinan tres aspectos: la especificidad de lo humano, lo vivo no humano, y de lo no vivo (cosas y objetos, bytes, etc.). Soy consciente de que estas distinciones son problemáticas, ya que la vida orgánica requiere de lo no orgánico para su emergencia. Pero me pregunto si tomar una posición para replantear la ciudad desde la perspectiva de lo vivo no humanos (terraformar) no debería ser parte de un posthumanismo crítico. Si este es el caso, tendría importantes implicaciones para el diseño de las interfaces y las interacciones.

Sería negligente si no mencionara, incluso de una manera muy breve, el elemento faltante en una agenda de investigación sobre el replanteamiento de lo urbano, que es su política. En las últimas dos décadas, he dedicado una gran atención a las luchas territoriales de los grupos étnicos en áreas rurales y forestales en Colombia y América Latina. Aunque aparentemente lejos de los problemas urbanos, creo que las lecciones generales de tales luchas son generalmente aplicables como principios y ejes estratégicos para los proyectos de reconfiguración de lo urbano desde perspectivas relacionales. Me refiero a los principios de autonomía, comunalidad (un neologismo acuñado por intelectuales y activistas en Oaxaca, México, para referirse al hecho históricamente específico de ser comunal) y la pluriversalidad. Para comenzar con esto último: los proyectos de terraformatividad son fundamentalmente pluriversales, en ambos sentidos de la palabra: como "un mundo donde quepan muchos mundos" (el principio zapatista para las luchas mundiales contra la globalización neoliberal); y como el flujo siempre cambiante de materia de la que surgen incesantemente formas interdependientes. Al traer de nuevo a la Tierra a la ciudad, asi sea de formas relativamente pequeñas, como en la propuesta de Martínez y algunos ejemplos de urbanismo biofílico, uno estaría contribuyendo a la política del pluriverso.

Personalmente, desarrollé las nociones de autonomía y de lo comunal extensamente en un libro reciente, Autonomía y diseño: la realización de lo comunal (2016; véase también 2014). Mi objetivo en este trabajo era llevar la autonomía al espacio de la teoría del diseño. Admite la posibilidad de que el diseño orientado ontológicamente pueda ser diseño para, y desde, la autonomía, en apoyo a las luchas mundiales contra las operaciones extractivas y en defensa de los territorios y mundos de los pueblos. Allí coloco los rudimentos de un marco de diseño autónomo, basado en la noción de autopoiesis de Maturana y Varela y en los debates latinoamericanos actuales sobre la autonomía y lo comunal, e ilustro la propuesta con dos experiencias que involucran el diseño autónomo y de transición en el suroeste de Colombia. En el pensamiento crítico latinoamericano actual, se entiende que lo comunal está siempre en proceso, como un dominio que cuestiona la hegemonía del individuo moderno como núcleo de la sociedad. La re-localización de actividades (comida, energía, transporte, educación, sanación) y la re-comunalización de la vida social emergen como principios críticos de autonomía y del rediseño.

No puedo desarrollar esta nociones en este texto más allá de esta breve explicación, aparte de enfatizar su papel fundamental en el pensamiento crítico latinoamericano y 
las luchas políticas en la actualidad. Muchas propuestas de transición ponen gran énfasis en la necesidad de re-localizar y re-comunalizar la existencia social. Hay dos criterios adicionales para las luchas enfatizados por los movimientos, también de gran importancia para el trabajo urbano. La primera es la necesidad de la descolonización y despatriarcalización simultáneas de la sociedad; como lo enuncian de manera concisa las feministas decoloniales, no hay descolonización sin despatriarcalización. El segundo, propuesto por los movimientos indígenas y algunos afrodescendientes, es la urgente necesidad de la Liberación de la Madre Tierra, poderosamente articulada por algunos activistas indígenas del pueblo Nasa del suroeste colombiano. Invito a los lectores a considerar que la descolonización, la despatriarcalización y la Liberación de la Tierra también pueden iluminar muchas de las tácticas y estrategias para repensar y rehacer la ciudad.

\section{CONCLUSIÓN}

Lo que está en juego al imaginar nuevas articulaciones entre sistemas vivos $y$ entramados infraestructurales, orientados metabólica y culturalmente, es el rediseño de la vida misma, de las condiciones para su florecimiento. Por eso tiene sentido hablar de transiciones civilizatorias. Martínez las sitúa en América Latina, pero su llamado resuena en todas partes. "Lenta pero seguramente, los pueblos de América Latina y el Caribe están comenzando a revalorizar el profundo significado del ser-al-estar-en característico del mundo natural" (2016: 197). Nos ayuda a visualizar la posibilidad de un despliegue hermoso de la fuerza autoorganizadora de la materia como agente de revitalización urbana creativa. Esta transición operaría en una multiplicidad de escalas y temporalidades, desde lo geológico a lo micro-orgánico, desde los suelos a la estructura de los materiales, desde las formas novedosas de ser humano a un devenir con lo no humano a través de la co-emergencia. Los diseñadores podrían llegar a concebir su práctica como la de ser tejedores conscientes y efectivos de la urdimbre de la vida (Escobar 2018a: 215). Existe un desafío en cómo traducir estos principios en herramientas para la gente y sus organizaciones. Esto podría involucrar el tipo de "arquitecturas insurgentes" previstas por un grupo de arquitectos colombianos para áreas emergentes pobladas por migrantes recién llegados a la ciudad (Montenegro, ed. 2018).

Esta visión podría servir como una contra propuesta en relación con los "territorios proscritos" que se han convertido en una parte tan central de la urbanización contemporánea, discutida por la teórica de la arquitectura Felicity Scott (2016), donde los aparatos biopolíticos neoliberales intentan contener y gobernar a los pobres, los desplazados, los indigentes, los migrantes, así como las minorías étnicas y sexuales marginadas, con el único objetivo de crear condiciones para la acumulación de capital, seguridad para los poderosos y un orden espacial que hacen imposibles formas significativas de convivencia humana y no humana. Uno puede cavilar sobre la posibilidad de que tal vez algún día los historiadores adelanten una extensa "arquitectura forense" (Weizman 2017) de las ruinas dejadas por tantas instancias de la ciudad modernista, para leer en ellas los efectos de las guerras, los drones, desplazamiento, 
conflictos ambientales, cambio climático, en resumen, todo lo que ocurrió cuando los humanos estaban tan ocupados acumulando y consumiendo que no se dieron cuenta de que habían expulsado a la Tierra de la ciudad.

Habría que preguntarse también si la reconfiguración de la ciudad desde la perspectiva de la Tierra discutida en este artículo es una posibilidad históricamente perdida, en cuyo caso solo pequeños enclaves de rurbanización podrían ser posibles aquí y allá, tal vez en las periferias de las ciudades, o en pueblos pequeños e irrelevantes, en los espacios de los expulsados en los límites de las órdenes globales (Sassen, 2014), o en las ciudades que deberán construirse para los refugiados climáticos y los desplazados de agravados conflictos y guerras. Sea como sea, al menos, estos serían espacios de curación, de re-comunalización y relaciones mutuamente enriquecedoras con la Tierra, lugares y espacios donde se habría introducido algún tipo de equilibrio biofísico basado en un metabolismo urbano diferente. Quizás haya

\section{REFERENCIAS}

ACIN (Asociación de Cabildos del Norte del Cauca). 2010. "Libertad para la Madre Tierra", http://www.nasaacin.org/ libertar-para-la-madre-tierra/50-libertadpara-la-madre-tierra, accessed July 5, 2018.

Amin, A. and Thrift, N., 2017. Seeing Like a City. Polity Press, Cambridge, UK.

Beatley, T., 2016. Handbook of Biophilic City Planning and Design. Island Press, Washington, D.C. una posibilidad de que esto suceda, en el espíritu del urbanismo experimental y las visiones de la ciudad como abiertas, permeables, y siempre des y re-construidas (por ejemplo, Simone y Pieterse 2017; Sennett 2018a, 2018b). Que eso constituya un camino para sanar nuestra cultura fragmentada.

Demos la última palabra a los sabios indígenas Nasa de Colombia, quienes han articulado de la manera más convincente el proyecto de Liberación de la Madre Tierra (ACIN 2010: 5).

$$
\begin{aligned}
& \text { Por eso, la lucha por la Tierra no } \\
& \text { es solo un deber de los pueblos } \\
& \text { indígenas; esunmandatoancestral } \\
& \text { para todos los pueblos, para todas } \\
& \text { las mujeres y hombres que desean } \\
& \text { defender la vida ... Ahí está, sí: } \\
& \text { entren, la puerta está abierta. }
\end{aligned}
$$

Nota: Agradezco a Carlos Tapia por acoger este texto en la Revista y por su excelente traducción del texto de su versión original en inglés

Beatley, T., 2011. Biophilic Cities. Integrating Nature into Urban Design and Planning. Island Press, Washington, D.C.

Burdett, R., 2018. Contemporary Urbanism. In: UN Habitat and Sennett, R. (Eds.). The Quito Papers and the New Urban Agenda. Routledge, New York, pp. 140149.

Bennett, J., 2010. Vibrant Matter. A Political Ecology of Things. Duke University Press, Durham. 
Borja, J., Carrión, F., 2017. Introducción:

Ciudades resistentes, ciudades posibles. In: Borja, J., Carrión, F., Corti, M. (Eds). Ciudades resistentes, ciudades posibles. Editorial OOC, Barcelona, pp. 17-58.

Capra, F., Luisi, P.L., 2014. The Systems View of Life. A Unifying Vision. Cambridge University press, Cambridge.

Cohen, S., 2018. The Sustainable City. Columbia University Press, New York.

Cronon, W., 1995. "The Trouble with Wilderness; or, Getting Back to the Wrong Nature." In W. Cronon, ed., Uncommon Ground: Rethinking the Human Place in Nature. New York: W.W. Norton.

Dávila, A., 2015. El Mall. The Spatial and Class Politics of Shopping Malls in Latin America. University of California Press, Berkeley.

Escobar, A., 2018.a Designs for the Pluriverse: Radical Interdependence, Autonomy, and the Making of Worlds. Duke University Press, Durham.

Escobar, A., 2018b. Autonomous Design and the Emergent Transnational Critical Design Studies Field. Strategic Design Research Journal 11(2): 139-146.

Escobar, A., 2016. Autonomía y diseño: la realización de lo comunal. Editorial Universidad del Cauca, Popayán.

Escobar, A., 2014. Sentipensar con la Tierra: Nuevas lecturas sobre desarrollo, territorialidad, y diferencia. UNAULA, Medellín.
Forlano, L., 2017. Posthumanism and Design.

She-ji. Journal of Design, Economics, and Innovation 3(1): 16-29.

Forlano, L., 2016. Decentering the Human in the Design of Collaborative Cities. Design Issues 32(3): 42-54.

Franklin, A., 2017. The more-than-human-city. Sociological Review 65(2): 202-17.

Fry, T., 2017. Re-Making Cities. An Introduction to Urban Metrofitting. Bloomsbury, London.

Fry, T., 2015. City Futures in the Age of a Changing Climate. Routledge, London.

Fry, T., 2012. Becoming Human by Design. Berg, London.

Gago, V., 2014. La razón neoliberal. Tinta Limón, Buenos Aires.

Gandy, M., 2012. Queer Ecology: Nature, Sexuality, and Heterotopic Alliances. Environment and Planning D: Society and Space 30: 727-747.

Gutiérrez Aguilar, R., 2017. Horizontes comunitario-populares. Traficantes de Sueños, Madrid.

Hecht, D., Simone, M.,1994. Invisible Governance. The Art of African Micropolitics. Autonomedia, New York.

Iglesias, V., García, H., 2016. Naturaleza y espacio. La arquitectura de Harold Martínez Espinal. Editorial Universidad del Valle, Cali.

Kirskey, E., 2015. Emergent Ecologies. Duke University Press, Durham.

Koolhas, R., 2014. Acerca de la ciudad. Editorial Gustavo Gili, Barcelona. 
Manifesto de Quito. 2017. In: Borja, J., Carrión, F., Corti, M. (Eds). Ciudades resistentes, ciudades posibles. Editorial OOC, Barcelona, pp. 311-325.

Marx, L., 1964. The Machine in the Garden. Technology and the Pastoral Ideal in America. New York: Oxford University Press.

Martínez Espinal, H., 2016. Del hábito, al hábitat y al habitar. Universidad del Valle, Cali.

Martínez Espinal, H., 2013. Habitabilidad terrestre y diseño. Universidad del Valle, Cali.

Massey, D., 2005. For Space. Sage, London.

Massey, D., 2004. "Geographies of Responsibility." Geografiska Annaler B 86(1) 2004: 5-18.

Montenegro, G. (Ed.) 2018. Insurgent architectures. Bogotá: Universidad Javeriana.

Nonini, D., (Ed.) 2014. A Companion to Urban Anthropology. John Wiley \& Sons, Malden, MA.

Roy, A., 2016. What is Urban about Critical Urban Theory? Urban Geography 37(6): 810-823.

Sassen, S., 2018. Who Owns the City? In: UN Habitat and Sennett, R. (Eds.) The Quito Papers and the New Urban Agenda. Routledge, New York, pp. 48-51.

Sassen, S., 2014. Expulsions. Brutality and Complexity in the Global Economy. Harvard University Press, Cambridge, MA.

Scott, F., 2016. Outlaw Territories: Environments of Insecurity/Architectures of counterinsurgency. Zone Books, New York.
Sennett, R., 2018a. Building and Dwelling. Ethics for the City. Farrar, Strauss and Giroux, New York.

Sennett, R., 2018b. “The Open City.” In UN Habitat, Sennett, R. (Eds.) The Quito Papers and the New Urban Agenda. Routledge, New York, 90-95.

Sennett, R., and Burdett, R., 2018. Preface. Why the Quito Papers? In: UN Habitat, Sennett, R. (Eds.), 2018. The Quito Papers and the New Urban Agenda. Routledge, New York, pp. $\mathrm{x}$-xiii.

Sennett, R., Clos, J., 2017. A Conversation. In: UN Habitat, Sennett, R. (Eds.). The Quito Papers and the New Urban Agenda. Routledge, New York, pp. 150-173.

Segato, R., 2015. La crítica de la colonialidad en ocho ensayos. Prometeo Libros, Buenos Aires.

Sharma, K., 2015. Interdependence: Biology and Beyond. Fordham University Press, New York.

Simone, A. M., Pieterse, E., 2017. New Urban Worlds. Inhabiting Dissonant Times. Polity Press, Cambridge, U.K.

Tsing, A., 2015. The Mushroom at the End of the World. Princeton University Press, Princeton.

UN Habitat, Sennett, R. (Eds.), 2018. The Quito Papers and the New Urban Agenda. Routledge, New York.

Valverde, M., 2011. “Seeing like a city: the dialectic of modern and premodern ways of seeing in urban governance." Law and Society Review 45(2): 277-312. 
Von Werlhof, C., 2011. The Failure of Modern Civilization and the Struggle for a 'Deep' Alternative. Frankfurt am Main: Peter Lang.

Williams, R.,1973. The Country and the City. New York: Oxford University Press.
Willis, A. M., 2006. “Ontological Designing Laying the Ground." Design Philosophy Papers, Collection Three: 80-98.

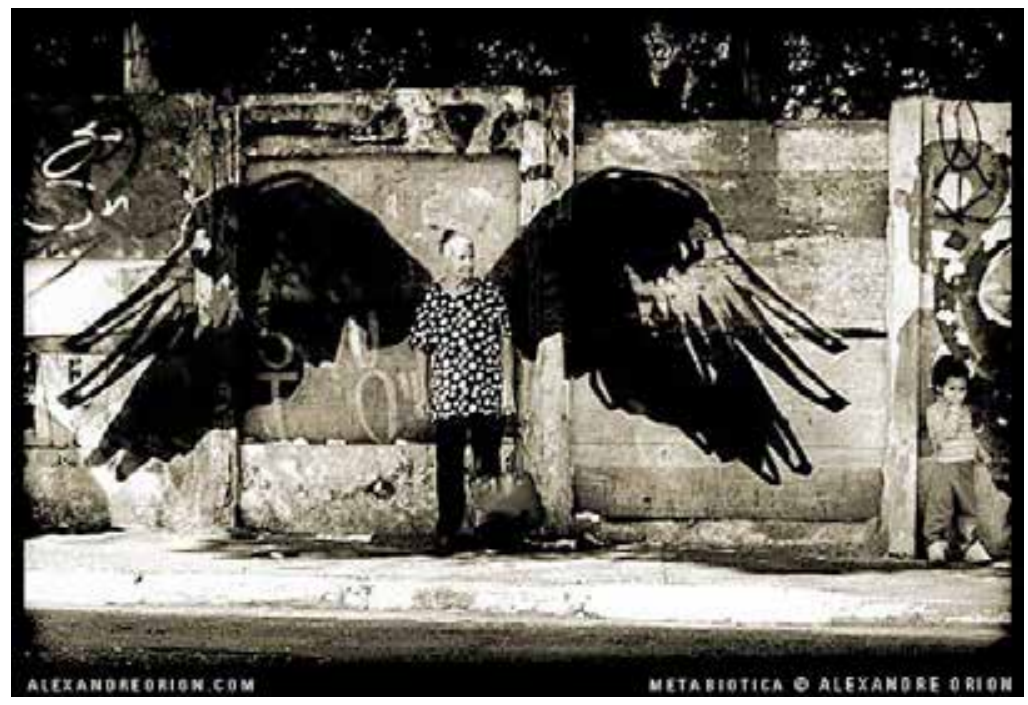

Metabiótica 4. 2002. Intervenção urbana seguida de registro fotográfico 